\title{
Variability in Some Biochemical and Nutritional Characteristics in Desi and Turkish Kabuli Chickpea (Cicer arietinum L.) Types
}

\author{
Tuğçe Kalefetoğlu Macar', Oksal Macar ${ }^{1}$, Dürdane İnci Mart ${ }^{2}$ \\ ${ }^{1}$ Giresun University, Şebinkarahisar School of Applied Sciences, Department of Food Technology, Giresun, \\ Tel: +90 45431017 10, Fax: +90 4543101717 \\ tugce.macar@giresun.edu.tr \\ oksal.macar@giresun.edu.tr \\ ${ }^{2}$ Republic of Turkey Ministry of Food, Agriculture and Livestock, Eastern Mediterranean Agricultural Research \\ Institute, Adana, Tel: +90 32233400 55, Fax: +90 3223340357 \\ durdanemart@yahoo.com \\ *Corresponding Author
}

Received: 27 March 2017

Accepted: 3 July 2017

DOI: $10.18466 /$ cbayarfbe.339330

\begin{abstract}
Chickpea (Cicer arietinum L.), the third most widely produced food legume in all over the world, is consumed for its protein-rich seeds especially in developing countries. According to seed morphology, cultivated chickpeas are of two types as desi and kabuli. There is a growing interest if extracts obtained from chickpea grains might be used as a source of natural antioxidants and antimicrobials such as phenolic or flavonoid compounds. The objective of this work is to investigate the total phenolic, flavonoid and protein contents of a desi (ICC 3996) type and three kabuli (Seçkin, İnci and Hasanbey) types of chickpea seeds. Analyses were performed in extracts of 24 hours imbibed grains. The Folin Ciocalteu procedure was used to assess the total phenolic amounts while the total flavonoid content was measured with an aluminium chloride colorimetric assay. Total protein concentration was determined according to the Biuret method. Desi type exhibited the lowest protein content whereas Inci had the highest levels of total protein among kabuli types. Total phenolic content of desi type was significantly higher than other genotypes $(P \leq 0.05)$. Seçkin showed lower flavonoid content than all other genotypes including the desi type. The results revealed that despite Turkish genotypes were richer in protein level, desi type was still valuable for its high total phenolic and flavonoid amounts.
\end{abstract}

Keywords: Chickpea, Desi, Flavonoid, Grain, Kabuli, Phenolic, Protein.

\begin{abstract}
1 Introduction
Chickpea (Cicer arietinum L.) is a leguminous plant known to contain high nutritional properties, due mainly to its seed protein content [1]. As an annual grain legume, it is important not only for its highly nutritive value but also for its ability to maintain soil fertility by fixing atmospheric nitrogen [2]. It is the world's third most important food legume crop [3]. It is cultivated throughout the world, including the Mediterranean basin, the Near East, Central and South Asia, East Africa, South and North America and Australia [4]. India, Turkey and Pakistan are considered as the major chickpea producers [5]. Based on their seed color and geographic distribution, chickpea biotypes are divided into two distinct groups as kabuli and desi [6]. In India and Pakistan, the chickpeas grown are Desi type, whereas Kabuli type chickpeas are grown mainly by Turkey [7]. Desi (originated from India) cultivars have small,
\end{abstract}

wrinkled and dark coloured seeds and Kabuli (originated from Mediterranean and the Middle East) cultivars have large, smooth coated and white to cream coloured [8].

Chickpea seeds are used for food and feed purposes, not only for excellent nutritional value but also for rich bioactive compound contents, such as phenolics and flavonoids [9]. Phenolic compounds are secondary metabolites that are the most widely found groups of phytochemicals in plants. These compounds have considerable physiological and morphological importance in plants. They play a crucial role in growth and reproduction, providing protection against pathogens and predators, besides contributing towards the colour and sensory characteristics of fruits and seeds [10, 11]. Phenolic compounds provide a wide range of biological properties such as anti-allergenic, anti-atherogenic, antiinflammatory, antimicrobial, anti-thrombotic, 
cardioprotective and vasodilatory effects. Further, they exhibit an antioxidant activity to prevent lipid peroxidation and scavenge free radicals [11, 12, 13]. One of the main groups of phenolic compounds found in grain legumes is flavonoids [11], a class of low molecular weight, secondary plant phenolics. They are the largest group of plant phenolics, accounting for over half of the eight thousand naturally occurring phenolic compounds and widely distributed in the leaves, seeds, bark and flowers [14]. In plants, these compounds afford protection against ultraviolet radiation, pathogens, and herbivores. In addition to protective roles in plants, they have beneficial health effects attributed to their antioxidant and chelating abilities in human diets [13]. Indeed, the preservative effects of flavonoids in biological systems are ascribed to their capacity to transfer electrons to free radicals, chelate metal catalysts, activate antioxidant enzymes, reduce alpha-tocopherol radicals, and inhibit oxidases [15, 16, 17, 18].

It was shown that kabuli seeds are more nutritive in respect to their protein content [8], however, chickpeas with dark seed coat (desi) are known for their higher antioxidant activity, arising from the phenolics fraction [4]. To the best of our knowledge, only a few studies have investigated these properties of chickpea seed flour. The objective of the current study was to compare the total phenolic content (TPC), total flavonoid content (TFC) and total protein content in a desi and three Turkish kabuli chickpea genotypes.

\section{Materials \& Methods}

In the present work, grains of a desi (ICC 3996) type and three kabuli (Seçkin, İnci and Hasanbey) types of Cicer arietinum were screened spectrophotometrically for their total phenolic, flavonoid and protein contents. The seeds of all genotypes were obtained from Eastern Mediterranean Agricultural Research Institute, Adana, Turkey.

Seeds were surface sterilized in $2 \%$ sodium hypochlorite (NaOCl) solution for $20 \mathrm{~min}$. Thereafter, they were washed and imbibed with distilled water. Seeds were grounded into flour by using an electric grinder. Powdered seeds were extracted and analyzed for the total phenolic and flavonoid contents according to Marinova et al. (2005) [19]. $0.5 \mathrm{~g}$ ground sample obtained from 24 hours imbibed grains was weighted for extractions. Phenolic and flavonoid compounds were extracted with $50 \mathrm{ml} \mathrm{80 \%} \mathrm{aqueous} \mathrm{methanol} \mathrm{and} \mathrm{were} \mathrm{sonicated} \mathrm{for} 20$ min. An aliquot $(2 \mathrm{ml})$ of the extracts was centrifugated for $5 \mathrm{~min}$ at $14000 \mathrm{rpm}$. The Folin-Ciocalteu assay was used to determine the total phenolic content of seeds. 1 $\mathrm{ml}$ of extract was added to $25 \mathrm{ml}$ volumetric flask, containing $9 \mathrm{ml}$ of distilled deionized (dd) water. A reagent blank using dd $\mathrm{H}_{2} \mathrm{O}$ instead of the extract was prepared. One millilitre of Folin-Ciocalteu's phenol reagent was added to mixture and flask was shaken thoroughly. After $5 \mathrm{~min}, 10 \mathrm{ml}$ of $7 \% \mathrm{Na}_{2} \mathrm{CO}_{3}$ solution was added to mixture. The solution was diluted to $25 \mathrm{ml}$ volume with dd $\mathrm{H}_{2} \mathrm{O}$ and the mixture was allowed to stand for 90 min with intermittent shaking at room temperature. The absorbance against blank was measured at $750 \mathrm{~nm}$ with a (UV mini 1240 Shimadzu) spectrophotometer. The same procedure was repeated to all standard solutions of gallic acid (20-100 mg/l) and a standard curve was obtained. Total phenolic content of seeds was calculated as mg gallic acid equivalents ((GAE)/100 g of extract) using the regression equation between gallic acid standards and $\mathrm{A}_{750}$. All samples were analysed in triplicates.

Total flavonoid constituents of seed extracts were performed employing the literature methods involving aluminum chloride colorimetric assay and catechin as standard (10). $1 \mathrm{ml}$ extract was added to10 ml flask containing $4 \mathrm{ml}$ of distilled deionized water. A reagent blank using dd $\mathrm{H}_{2} \mathrm{O}$ instead of the extract was prepared at this stage. $0.3 \mathrm{ml} 5 \% \mathrm{NaNO}_{2}$ was added to the flask and the flask was vortexed immediately and waited 5 min. Then, $0.3 \mathrm{ml} 10 \% \mathrm{AlCl}_{3}$ solution was added to the mixture and waited 5 more min. At $6^{\text {th }} \min , 2 \mathrm{ml} 1 \mathrm{M}$ $\mathrm{NaOH}$ was added and the total volume was diluted to 10 ml with dd $\mathrm{H}_{2} \mathrm{O}$. The solution was vortexed vigorously and absorbance was measured against blank at $510 \mathrm{~nm}$ with a (UV mini 1240 Shimadzu) spectrophotometer. All procedure was repeated to all standard solutions of catechin (20-100 mg/l) and a standard curve was obtained. Total flavonoid content of extracts was calculated as $\mathrm{mg}$ catechin equivalents ((CE)/100 g of extract) using the regression equation between catechin standards and $A_{510}$. All samples were analysed in triplicates.

The total protein content of each extract was investigated using the Biuret method [20]. 0.5 g grounded material obtained from 24 hours imbibed grains was extracted in $1.5 \mathrm{ml}$ potassium phosphate buffer $(0.1 \mathrm{mM}, \mathrm{pH}=7.5)$. The calibration curve was prepared with bovine serum albumin $(0.1-1.0 \mathrm{mg} / \mathrm{ml})$. Total protein concentrations were determined at $540 \mathrm{~nm}$ spectrophotometrically. Total protein content of extracts was expressed as $\mathrm{mg} / \mathrm{ml}$. The process was repeated three times for all extracts.

The results obtained were statistically analyzed with the Student's T-test using a significance level of $P \leq 0.05$.

\section{Results \& Discussion}

Chickpea is a good source of protein which constitutes about $80 \%$ of the total dry seed mass with carbohydrates [21]. Among the different grain legumes, chickpea has been reported to have a higher protein bioavailability [21, 22]. All data obtained from the total protein content analyses of genotypes varied significantly $(P \leq 0.05)$. Total protein levels of genotypes ranged between 18.6 $\mathrm{mg} / \mathrm{ml}$ and $27.1 \mathrm{mg} / \mathrm{ml}$ (Figure 1). İnci exhibited the highest levels of protein among all chickpea genotypes while the desi type, ICC 3996, had the least level of 18.6 
$\mathrm{mg} / \mathrm{ml}$. Among kabuli types, total protein amount of İnci was followed by Seçkin $(21.9 \mathrm{mg} / \mathrm{ml})$ and Hasanbey $(24.1 \mathrm{mg} / \mathrm{ml})$. Our results were in agreement with other findings. Kaur and Sing [23], indicated that kabuli chickpea protein isolates showed significantly higher protein amounts than desi types. Moreover, Sharma et al. [24], found out that crude protein content was higher in kabuli lines than that of desi lines.

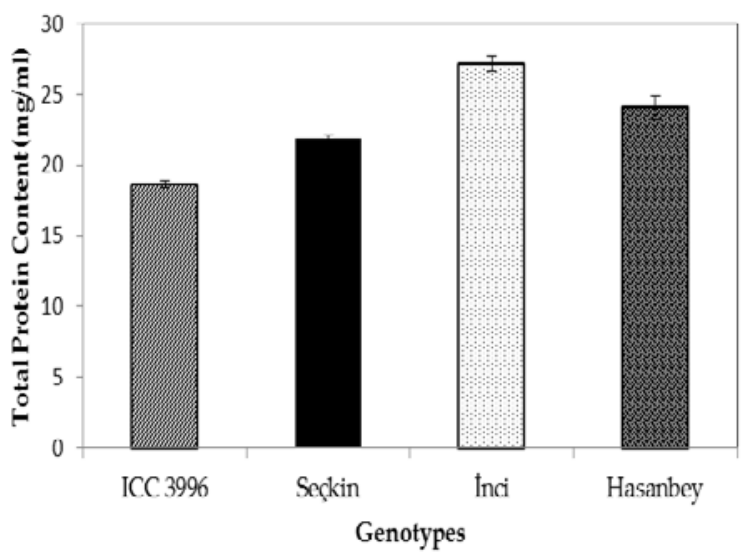

Figure 1. Total protein content in chickpea seeds.

Dry legumes are staple and potentially functional foods, being good sources of polyphenols and flavonoids [4]. Besides their nutritional value, chickpea seeds contain various phenolic compounds [25]. Phenolic compounds are of particular interest because of their contribution to the seed colour and sensory characteristics as well as several biological properties [9].

Total phenolic content of desi type was $128.8 \mathrm{mg}$ GAE/100 g seed and was significantly higher than other genotypes $(P \leq 0.05)$ (Figure 2$)$. Total phenolic levels of Seçkin, İnci and Hasanbey were $120.3 \mathrm{mg} \mathrm{GAE} / 100 \mathrm{~g}$, $122.6 \mathrm{mg}$ GAE/100 g and $119.2 \mathrm{mg}$ GAE/100 g, respectively.

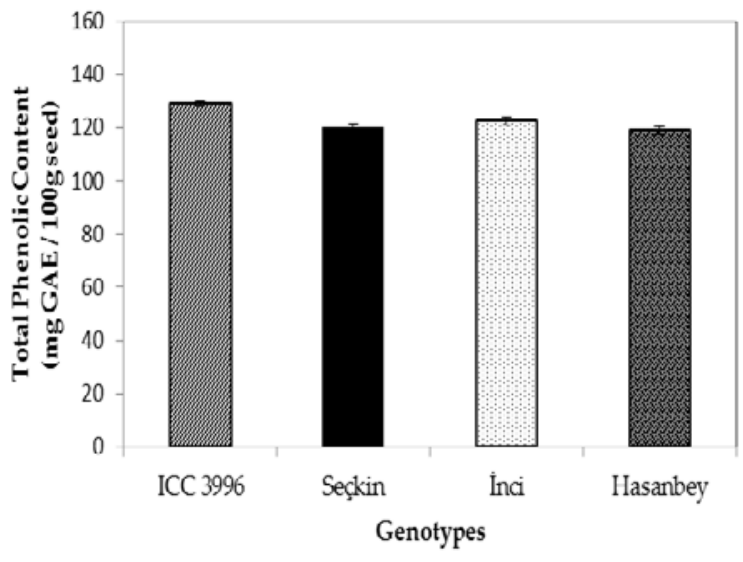

Figure 2. Total phenolic content in chickpea seeds.

Among kabuli chickpea seeds no significant difference was observed in the total phenolic levels. On the contrary to our data, Maheri-Sis et al. [26], found similar results in total phenolic content of desi and kabuli types. On the other hand, Sing and Jambunathan [27], noted that polyphenolic compounds in desi seeds were more than twice that of kabuli. However, these compounds were in negative correlation with in vitro digestibility of protein.

One of the main groups of phenolic compounds found in grain legumes is flavonoids [9]. Significant differences were found in the total flavonoid content among the studied genotypes. In contrary to the total phenolics, Seçkin seeds showed the least total flavonoid content (109.5 mg CE/100 g) among all other genotypes (Figure 3). The total flavonoid level of ICC 3996 (116.2 mg $\mathrm{CE} / 100 \mathrm{~g}$ ) was close to those of İnci (114.3 mg CE/100 g) and Hasanbey (118.1 mg CE/100 g). Hasanbey had the highest total flavonoid content in kabuli types but there was no significant difference in flavonoid levels of Hasanbey and ICC 3996. Although Segev et al. [4], pointed out that seed coat usually contains more than $95 \%$ of phenolics and flavonoids and coloured seeds contain these compounds much more than cream- and beige-coloured seeds, our desi type showed flavonoid content as much as kabuli types.

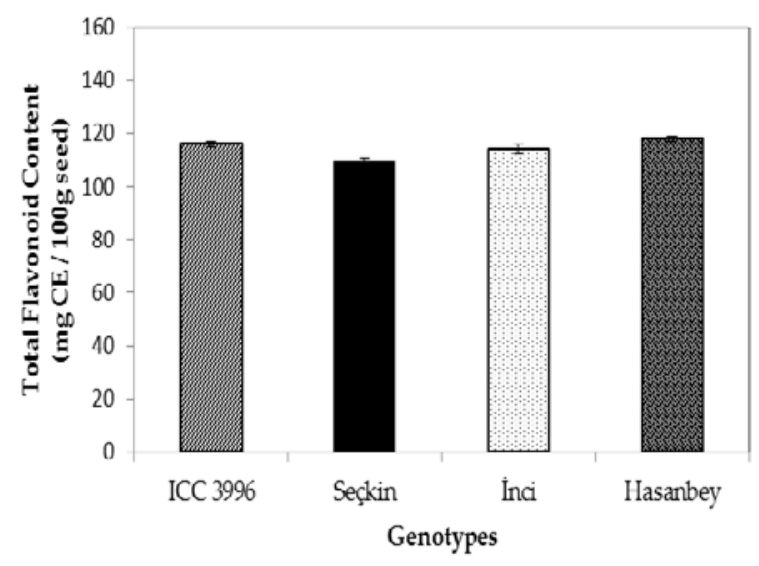

Figure 3. Total flavonoid content in chickpea seeds.

\section{Conclusion}

Results verified that total phenolic level of chickpea grains may be associated with seed colour. Analysed chickpea genotypes can be considered as therapeutic functional foods due to their extraordinary reserve of bioactive compounds such as phenolics and flavonoids besides their rich protein content. In addition, chickpea seed flour can be used for an ideal complement to a healthy diet or to enrich the functional foods. However further studies are needed to monitor and characterize the other antioxidant properties in chickpea grains.

\section{References}

1. Kalefetoğlu Macar, T, Ekmekçi, Y, Alterations in photochemical and physiological activities of chickpea (Cicer arietinum L.) cultivars under drought stress, Journal of Agronomy and Crop Science, 2009, 195(5), 335-346.

2. Agarwal, G, Jhanwar, S, Priya, P, Singh, V.K, Saxena, M.S, Parida, S.K, Garg, R, Tyagi, A.K, Jain, M, Comparative analysis of kabuli 
chickpea transcriptome with desi and wild chickpea provides a rich resource for development of functional markers, Public Library of Science One, 2012, 7(12), e52443.

3. Jain, M, Misra, G, Patel, R.K, Priya, P, Jhanwar, S, Khan, A.W, Shah, N, Singh, V.K, Garg, R., Jeena, G, Yadav, M, Kant, C, Sharma, P, Yadav, G, Bhatia, S, Tyagi, A.K, Chattopadhyay, D, A draft genome sequence of the pulse crop chickpea (Cicer arietinum L.), The Plant Journal, 2013, 74(5), 715-729.

4. Segev, A, Badani, H, Galili, L, Hovav, R, Kapulnik, Y, Shomer, I, Galili, S, Total phenolic content and antioxidant activity of chickpea (Cicer arietinum L.) as affected by soaking and cooking conditions, Food and Nutrition Sciences, 2011, 2, 724-730.

5. Ghribi, A.M, Maklouf, I, Blecker, C, Attia, H, Besbes, S, Nutritional and compositional study of desi and kabuli chickpea (Cicer arietinum L.) flours from Tunisian cultivars, Advances in Food Technology and Nutrition Sciences Open Journal, 2015, 1(2), 38-47.

6. Wang, X, Gao, W, Zhang, J, Zhang, H, Li, J, He, X, Ma, H, Subunit, amino acid composition and in vitro digestibility of protein isolates from Chinese kabuli and desi chickpea (Cicer arietinum L.) cultivars, Food Research International, 2010, 43(2), 567-572.

7. Aydemir, L.Y, Yemenicioğlu, A, Potential of Turkish kabuli type chickpea and green and red lentil cultivars as source of soy and animal origin functional protein alternatives, LWT-Food Science and Technology, 2013, 50(2), 686-694.

8. Purushothaman, R, Upadhyaya, H.D, Gaur, P.M, Gowda, C.L.L, Krishnamurthy, L, Kabuli and desi chickpeas differ in their requirement for reproductive duration, Field Crop Research, 2014, 163, 24-31.

9. Magalhães, S.C, Taveira, M, Cabrita, A.R, Fonseca, A.J, Valentão, P, Andrade, P.B, European marketable grain legume seeds: further insight into phenolic compounds profiles, Food Chemistry, 2017, 215, $177-184$.

10. Padhi, E.M, Liu, R, Hernandez, M, Tsao, R, Ramdath, D.D, Total polyphenol content, carotenoid, tocopherol and fatty acid composition of commonly consumed canadian pulses and their contribution to antioxidant activity, Journal of Functional Foods, 2016, In Press.

11. Balasundram, N, Sundram, K, Samman, S, Phenolic compounds in plants and agri-industrial by-products: antioxidant activity, occurrence, and potential uses, Food Chemistry, 2006, 99(1), 191-203.

12. Forman, H.J, Davies, K.J.A, Ursini, F, How do nutritiona antioxidants really work: nucleophilic tone and para-hormesis versus free radical scavenging in vivo, Free Radical Biology and Medicine, 2014, 66(8), 24-35.

13. Heim, K.E, Tagliaferro, A.R, Bobilya, D.J, Flavonoid antioxidants: chemistry, metabolism and structure-activity relationships, The Journal of Nutritional Biochemistry, 2002, 13, 572-584.

14. Harborne, J.B, Williams, C.A, Advances in flavonoid research since 1992, Phytochemistry, 2000, 55, 481-504.
15. Hirano, R, Sasamoto, W, Matsumoto, A, Itakura, H, Igarashi, O, Kondo, K, Antioxidant aAbility of various flavonoids against DPPH radicals and LDL oxidation, Journal of Nutritional Science and Vitaminology (Tokyo), 2001, 47, 357-362.

16. Cos, P, Ying, L, Calomme, M, Hu, J.P, Cimanga, K, Van Poel, B, Pieters, L, Vlietnck, A.J, Vanden Berghe, D, Structure-activity relationship and classification of flavonoids as inhibitors of xanthine oxidase and superoxide scavengers, Journal of Natural Products, 1998, $61,71-76$.

17. Ferrali, M, Signorini, C, Caciotti, B, Sugherini, L, Ciccoli, L, Giachetti, D, Comporti, M, Protection against oxidative damage of erythrocyte membranes by the flavonoid quercetin and its relation to iron chelating activity, FEBS Letters, 1997, 416, 123-129.

18. Elliott, A.J, Scheiber, S.A, Thomas, C, Pardini, R.S, Inhibition of glutathione reductase by flavonoids, Biochemical Pharmacology, 1992, 44, 1603-1608.

19. Marinova, D, Ribarova, F, Atanassova, M, Total phenolics and total flavonoids in bulgarian fruits and vegetables, Journal of Chemical Technology and Metallurgy, 2005, 40(3), 255-260.

20. Doumas, B.T, Waston, W.A, Biggs, A.G, Biuret method for quantitative estimation of total protein in serum or plasma, Clinica Chimica Acta, 1971, 31, 87-91.

21. Jukanti, A.K, Gaur, P.M, Gowda, C.L.L, Chibbar, R.N, Nutritional quality and health benefits of chickpea (Cicer arietinum L.): a review, British Journal of Nutrition, 2012, 108, 11-26.

22. Yust, M, Pedroche, J, Giron-Calle, J, Alaiz, M, Millán, F, Vioque, $\mathrm{J}$, Production of ace inhibitory peptides by digestion of chickpea legumin with alcalase, Food Chemistry, 2003, 81(3), 363-369.

23. Kaur, M, Singh, N, Characterization of protein isolates from different Indian chickpea (Cicer arietinum L.) cultivars, Food Chemistry, 2007, 102(1), 366-374.

24. Sharma, S, Yadav, N, Singh, A, Kumar, R, Nutritional and antinutritional profile of newly developed chickpea (Cicer arietinum L.) varieties, International Food Research Journal, 2013, 20(2), 805810.

25. Wood, J.A, Grusak, M.A, Nutritional value of chickpea. In: Yadav, S.S, Redden, R.J, Chen, W, Sharma, B (eds) The chickpea breeding and management, Cabi Publishing: Trowbridge, UK, 2007, pp 101-142.

26. Maheri-Sis, N, Chamani, M, Ali-Asghar, S, Mirza-Aghazadeh, A, Aghajanzadeh-Golshani, A, Nutritional evaluation of kabuli and desi type chickpeas (Cicer arietinum L.) for ruminants using in vitro gas production technique, African Journal of Biotechnology, 2008, 7(16), 2946 - 2951.

27. Singh, U, Jambunathan, R, Studies on desi and kabuli chickpea (Cicer arietinum L.) cultivars: levels of protease inhibitors, levels of polyphenolic compounds and in vitro protein digestibility, Journal of Food Science, 1981, 46(5), 1364-1367. 